University of Nebraska - Lincoln

DigitalCommons@University of Nebraska - Lincoln

Publications, Agencies and Staff of the U.S.

Department of Commerce

U.S. Department of Commerce

2011

A simple photograph-based approach for discriminating between free-ranging long-finned (Globicephala melas) and short-finned (G. macrorhynchus) pilot whales off the east coast of the United States

Brenda K. Rone

National Oceanic and Atmospheric Administration, brenda.rone@noaa.gov

Richard M. Pace III

National Oceanic and Atmospheric Administration

Follow this and additional works at: https://digitalcommons.unl.edu/usdeptcommercepub

Part of the Environmental Sciences Commons

Rone, Brenda K. and Pace, Richard M. III, "A simple photograph-based approach for discriminating between free-ranging long-finned (Globicephala melas) and short-finned (G. macrorhynchus) pilot whales off the east coast of the United States" (2011). Publications, Agencies and Staff of the U.S. Department of Commerce. 311.

https://digitalcommons.unl.edu/usdeptcommercepub/311

This Article is brought to you for free and open access by the U.S. Department of Commerce at DigitalCommons@University of Nebraska - Lincoln. It has been accepted for inclusion in Publications, Agencies and Staff of the U.S. Department of Commerce by an authorized administrator of DigitalCommons@University of Nebraska - Lincoln. 
MARINE MAMMAL SCIENCE, $* *(*): * * * \_* * *(* * * 2011)$

2011 by the Society for Marine Mammalogy

Published 2011. This article is a US Government work and is in the public domain in the USA.

DOI: $10.1111 / \mathrm{j} .1748-7692.2011 .00488 . x$

\title{
A simple photograph-based approach for discriminating between free-ranging long-finned (Globicephala melas) and short-finned (G. macrorbynchus) pilot whales off the east coast of the United States
}

\author{
BRENDA K. RONE \\ National Marine Mammal Laboratory, \\ National Marine Fisheries Service, \\ National Oceanic and Atmospheric Administration, \\ 7600 Sand Point Way NE, \\ Seattle, Washington 98115 , U.S.A. \\ E-mail: brenda.rone@noaa.gov \\ Richard M. PACE, III \\ Northeast Fisheries Science Center, \\ National Marine Fisheries Service, \\ National Oceanic and Atmospheric Administration, \\ 166 Water Street, \\ Woods Hole, Massachusetts 02543, U.S.A.
}

\begin{abstract}
Line transect based abundance estimation is complicated for long-finned (LFPW, Globicephala melas) and short-finned (SFPW, G. macrorbynchus) pilot whales because of their similarity in appearance and their overlapping summertime range in some areas. We developed a photograph-based approach to distinguish between species of free-ranging pilot whales in the northwest Atlantic. We collected skin samples and photographs during the summers of 2004-2007 and used skin samples to distinguish species based on mitochondrial DNA. Relative morphometric measurements from photographs were examined using mixed-effect models and logistic regression. The best model among 94 candidate models had an overall classification error rate of $2.5 \%$. We tested the presence/absence of pigmentation in four regions of the dorsal body (melon, eye, cape, and saddle) for differences. Pigmentation was present in all four regions in $100 \%$ of the SFPWs sampled. Melon patch, blaze, and saddle patch pigmentation were present in $6 \%, 68 \%$, and $50 \%$, respectively, of the LFPWs, but the cape was completely absent. Both types of analyses provided positive species discrimination of free-ranging animals. We created a cost-effective, simple tool which could ultimately assist in providing appropriate management, mitigation, and conservation strategies for both northwest Atlantic species of pilot whales.
\end{abstract}

Key words: pilot whale, NMFS Stock Assessment Report, morphometrics, pigmentation, mixed-effect model, logistic regression. 
Long-finned (LFPW, Globicephala melas) and short-finned (SFPW, G. macrorbynchus) pilot whales look similar at sea. They are both black to brownish gray with a thick tail stock, bulbous head, and a broad, falcate dorsal fin. Pigmentation characters can include a postorbital eye blaze, a postdorsal saddle patch, and a cape that connects the blaze and the saddle (Kasuya et al. 1988, Stacey and Baird 1993, Jefferson et al. 2008). Although these two species are readily distinguishable using osteological characters such as tooth counts and skull morphology (Sergeant 1962a, Olson and Reilly 2002) or by genetic analyses (May-Collado and Agnarsson 2006, Oremus et al. 2009), they are generally considered not to be predictably distinguishable at sea by physical characteristics alone (Olson and Reilly 2002, Jefferson $e t$ al. 2008). In some areas, (e.g., the northwest Atlantic) their ranges overlap; thus this difficulty in identifying individuals to species limits at-sea studies.

Geographic variations of these two species are discussed in the literature (Cope 1876; Rayner 1939; Davies 1960, Sergeant 1962a, b; Yonekura et al. 1980; Gaskin 1982; Kasuya et al. 1988; Bloch and Lastein 1993; Bloch et al. 1993b; Jefferson et al. 2008), though few morphometric and pigmentation comparisons have been made between these two species, particularly those found in the northwest Atlantic. Morphological (Yonekura et al. 1980, Kasuya et al. 1988, Bloch and Lastein 1993, ICES 1993, Perryman and Lynn 1993, Wang et al. 2000) and pigmentation (Perrin 1972, Yonekura et al. 1980, Evans et al. 1982, Baird and Stacey 1988, Koopman and Gaskin 1994, Pitman and Ensor 2003) analyses have been accepted methods for discriminating among other species and subpopulations of odontocetes.

Understanding potential anthropogenic impacts (e.g., fisheries) to both species of pilot whales in the northwest Atlantic, as reviewed in the U.S. Atlantic and Gulf of Mexico Marine Mammal Stock Assessment Report (SAR) assembled by the National Marine Fisheries Service (NMFS), is important to properly manage these populations. Their similarity of appearance and significant range overlap, and our inability to distinguish between them during assessment cruises, add uncertainty when describing the geographic range, estimating the minimum population size and human-induced mortality and serious injury rates, and calculating the potential biological removal level, which is required for each stock (Wade and Angliss 1997). To date, all SARs of northwest Atlantic pilot whales are inadequate; species-specific abundance estimates have not been produced due to the uncertainty of species identity within a large proportion of their putative summertime ranges (Waring et al. 2009).

In the northwest Atlantic, both pilot whale species feed on squid and display seasonal movement throughout their range along the eastern United States (Gannon et al. 1997a, b). In this geographic region, LFPWs have an antitropical distribution with a southern limit of North Carolina, and SFPWs are found in tropical waters with a northern limit of New Jersey (Leatherwood et al. 1976, Mead 1979). The shelf edge/slope water region is an important habitat for both species of pilot whales (Hain et al. 1985, Payne and Heinemann 1993, Hamazaki 2002), and in the northwest Atlantic, their ranges overlap during summer from approximately $35^{\circ} \mathrm{N}$ (Cape Hatteras, North Carolina) to $39^{\circ} \mathrm{N}$ (east of Delaware Bay) (Payne and Heinemann 1993). In this study, we developed a photograph-based approach to distinguish these two species of pilot whales in the northwest Atlantic. We collected and examined photographic images of pilot whales coincident with genetic sampling during five summer research cruises conducted in U.S. waters of the northwest Atlantic and from one stranded animal during the years 2004-2007. We examined the utility of physical features, such as relative shape or coloration that are detectable in photographs as useful discriminating characters. Ultimately, we developed a simple, cost-effective 
method for distinguishing free-ranging pilot whales in the northwest Atlantic, easily implemented as part of ship-based surveys.

\section{METHODS}

\section{Field Methods}

Field work was conducted in the month of July during each year in 2004-2007. This included four cruises conducted by the Northeast Fisheries Science Center (NEFSC) and one cruise in 2005 by the Southeast Fisheries Science Center (SEFSC). Each cruise collected genetic samples, photographic images, and acoustic records for investigation of pilot whale species identification. To maximize pilot whale encounters, tracklines were designed based on findings from past mammal surveys, bathymetric and oceanographic data, and weather conditions, with emphasis on the area of distribution overlap. Additional LFPW images were collected of one stranded animal from the Herring River on Cape Cod, Massachusetts $\left(41^{\circ} 56 \mathrm{~N}, 70^{\circ} 04^{\prime} \mathrm{W}\right)$ and from an opportunistic sighting on Jeffreys Bank in August 2006 during a marine mammal survey.

Two National Oceanic and Atmospheric Administration (NOAA) ships, the Delaware II (NEFSC) and Gordon Gunter (SEFSC), were used as survey platforms to search for pilot whales along predetermined tracklines. When pilot whales were located, small boats $(6-8 \mathrm{~m})$ were launched from the large vessel to collect photographs and skin samples. Photographic protocols were designed to maximize photographing opportunities while coordinating with biopsy effort. Key photography guidelines were to (1) photograph the animal so that it is perpendicular to the camera's focal plane, (2) collect suites of photographs that cover the dorsal side of the animal (apex of the melon to the saddle region), and (3) obtain focused photographs with minimal glare and proper exposure. When possible, a biopsy sample was collected simultaneously with a suite of photographs (Fig. 1). It was necessary to obtain this suite of images for biopsied animals whose species identification was determined via genetic markers so that morphometrics and pigmentation patterns could be compared with animals belonging to the same group that were not genetically sampled.

Several distinct groups milling in the same area or traveling in the same direction were considered an aggregation. Based on general observations, cohesiveness of groups appeared to be variable. Structure ranged from fission and fusion between groups within an aggregation, loose delineations between groups traveling in close proximity, and multiple separate groups merging together during periods of rest or possible foraging.

Images were collected using digital SLR cameras: Canon D301 (3.0 megapixels), 10D (6.3 mp), 20D (8.2 mp), and Nikon D70 (6.1 mp) as fine JPEG files. The number of images per animal ranged from one to three pictures. For all photographed animals, a unique sighting number was assigned that referenced the day of collection and the aggregation. Each animal was assigned a size class: "large" was assigned to adult males (easily identifiable from their sexually dimorphic characteristics, Olson and Reilly 2002), "medium" to adult females and subadult males, and "small" to juveniles (Fig. 2). Calves were excluded.

\footnotetext{
${ }^{1}$ Reference to trade names does not imply endorsement by the National Marine Fisheries Service, NOAA.
} 


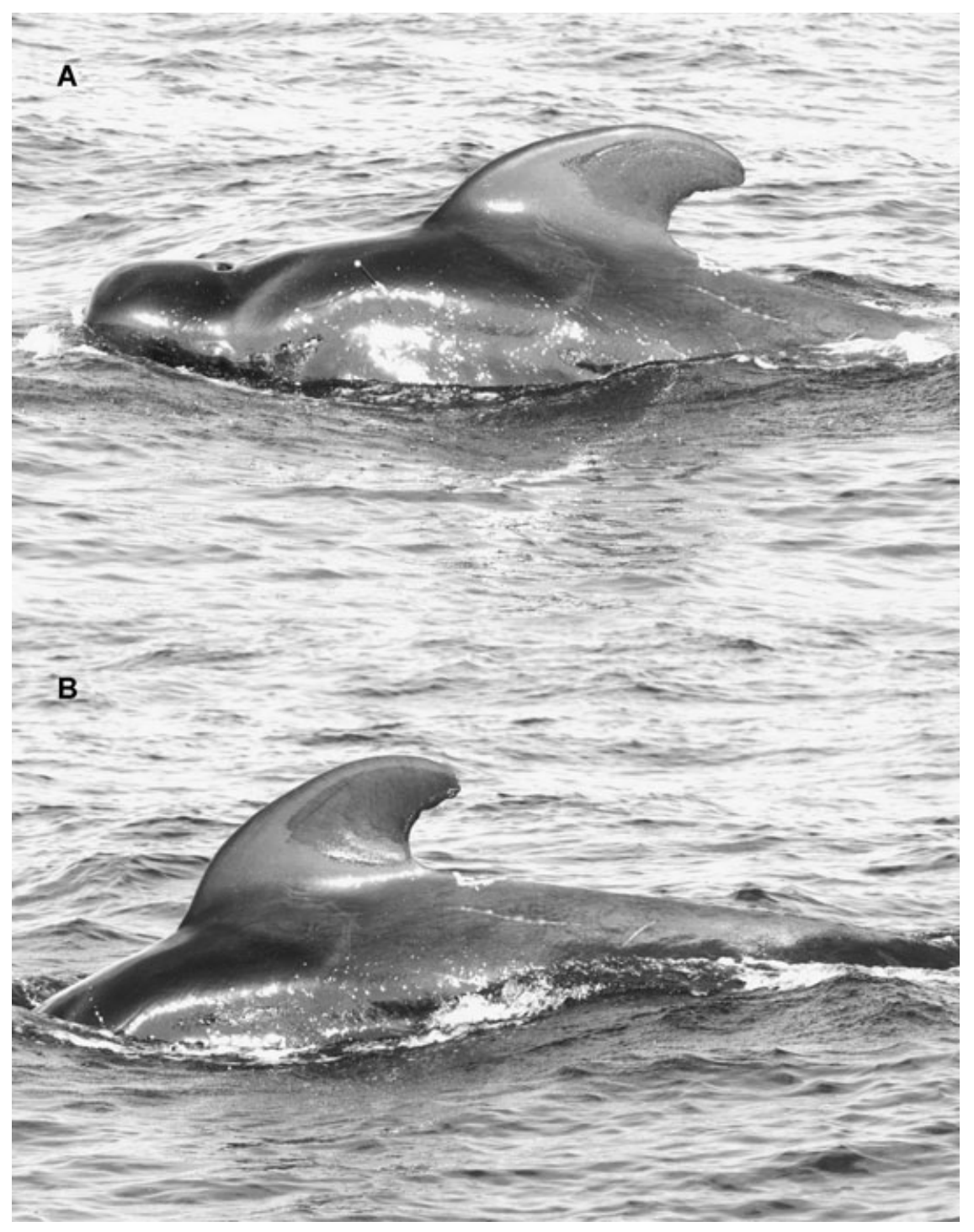

Figure 1. Example of photographs collected coincident with a genetic sample. Note the successful documentation of the entire animal from the apex of the melon to the tailstock ( $A$, $\mathrm{B})$, the perpendicular placement of the animal to the camera's focal plane, the sharp quality with proper exposure for color contrast, and documentation of the biopsy dart (A).

A target animal was selected based upon its position in relation to the boat, position within the group, and unique markings such as scars and dorsal fin notches to minimize resampling. The sampling objectives were two to three skin samples per group with associated perpendicular images. Throughout this process, the photographer would also collect perpendicular photographs of as many other individuals within each group as time permitted. 


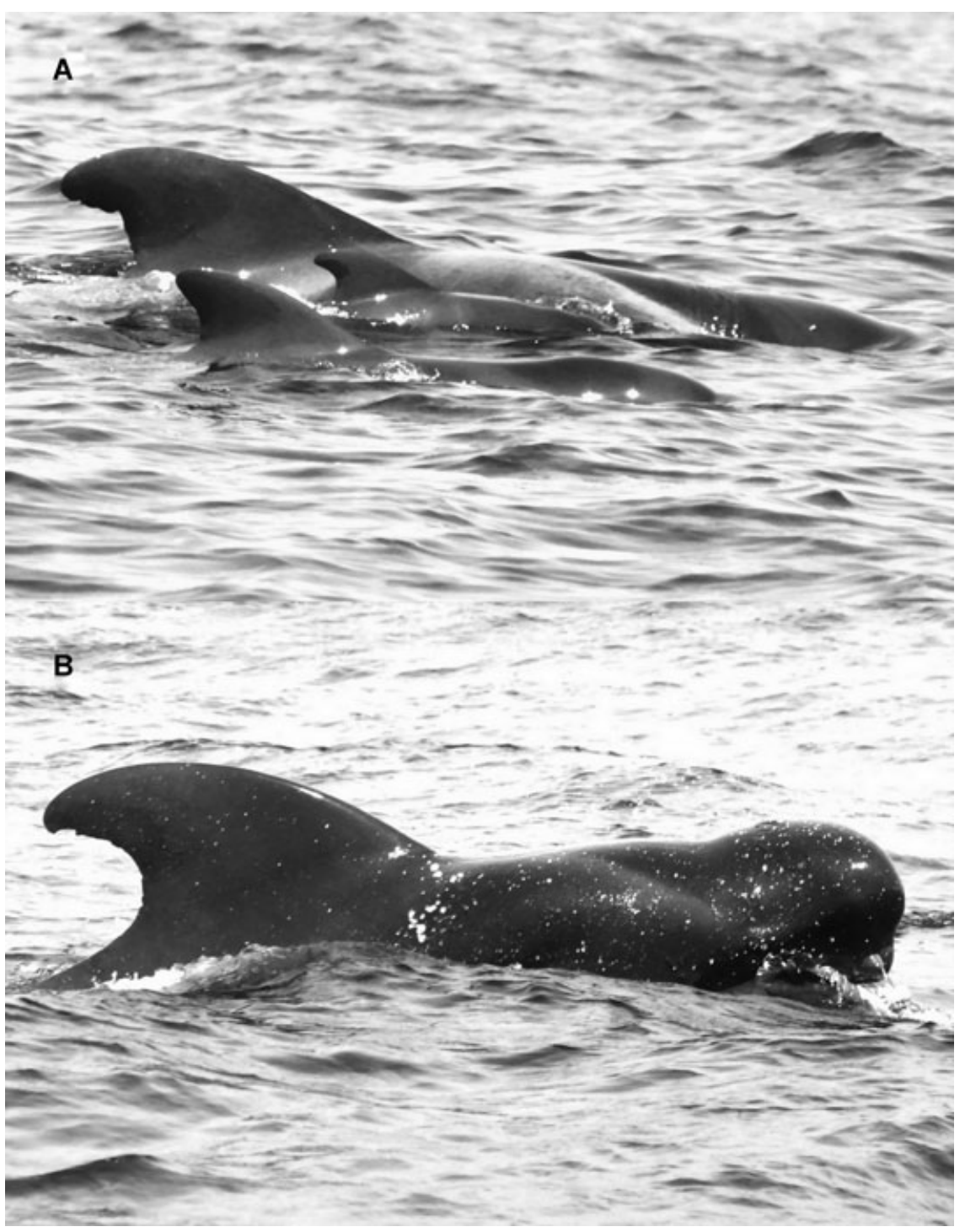

Figure 2. Examples of the three size class categories assigned to pilot whales, small (A, front animal), medium (A, back animal), and large (B). Calves were excluded from analysis but shown here (A, middle animal) for size reference. Note the bulbous head and oversized dorsal fin on large (B) - two sexually dimorphic characteristics easily distinguishable on adult males.

\section{Genetic Samples}

Genetic samples were collected using $68 \mathrm{~kg}$ crossbows and .22 caliber dart rifles with darts containing special tips designed to acquire a plug of skin. Samples were stored in vials containing salt and dimethyl sulfoxide (DMSO). DNA was extracted 
using standard organic extraction methods and the $5^{\prime}$ end of the mitochondrial DNA control region was amplified and sequenced on a 3130 Genetic Analyzer (Applied Biosystems by Life Technologies, Carlsbad, CA). Resultant sequences were identified to species through phylogenetic reconstruction incorporating sequences from animals of known taxonomic identity based on morphology. ${ }^{2}$ If duplicate sampling of an individual occurred, all information from that individual was combined.

\section{Image Processing}

At the end of each field sampling occasion, we sorted through images and used field records and dorsal fin characteristics such as scarring, relative size, and shape to match images to individuals. We believe that it is extremely unlikely that the same animals were sampled in multiple years. First, the best estimate of abundance is approximately 31,138 pilot whales in these two stocks (Waring et al. 2009) and we sampled from 26 sightings comprised of approximately 1,650 animals. Second, we sampled throughout an area of approximately $230,000 \mathrm{~km}^{2}$. We rarely sampled groups within the same $1^{\circ}$ block in multiple years and in one instance, east of Delaware Bay (Fig. 5), we located LFPWs in 2004 and SFPWs in 2006. Finally, given the amount of photograph culling that occurred for analyses, the chance duplication of individual animals between years, sampled over this large area, would be unlikely. Therefore, we only matched images within each annual survey. Pigmentation, dorsal fin outline-including notches on the leading and trailing edge-and scars were used to identify individual animals. Although some of these identifiers lack long-term stability (multiple years) (Auger-Méthé and Whitehead 2007), they are sufficient for individual identification within a survey in any 1 yr. Generic dorsal fins lacking unique shape, notches, or scars were treated as separate animals (unless documented in the field).

Ratios were calculated only from measurements derived from a single image. Based on results from a study that used a model whale to assess angle impact on these measurements (Rone 2009), images in which horizontal (angular) deviation of the target animal was $>10^{\circ}$ were excluded from the morphometric analysis, but used in the pigmentation analysis. All photographs that documented any region from the melon to posterior to the dorsal fin, despite lack of a complete profile in a single image, were included for pigmentation comparisons.

\section{Morphometrics}

Measurements of whale features (Table 1, Fig. 3) evaluated for their performance on a whale model by Rone (2009) were taken from pilot whale images using the software program Image Pro Plus 5.0 (Media Cybernetics, Inc., Bethesda, MD). The eye was only rarely captured in otherwise high-quality images. Therefore, relative measurements using this feature were excluded from analysis. Images in which the whale was vertically displaced were rotated until the measurement axis reference was horizontal to the image frame (Rone 2009). This operation allowed for more consistent establishment of reference lines. The angular deviation of the whale's position from the camera focal plane was quantified (Rone 2009). On the accepted images (angular deviation $\leq 10^{\circ}$ ), reference lines were established (Fig. 3), pixels for

\footnotetext{
${ }^{2}$ Unpublished data from P. Rosel, NOAA Fisheries, SEFSC/Estuarine Habitats and Coastal Fisheries Center, 646 Cajundome Boulevard, Lafayette, LA 70506, January 2011.
} 
Table 1. Seven morphological features measured on pilot whale images for species discrimination.

\begin{tabular}{lc}
\hline \hline Description & Abbreviation \\
\hline Apex of melon to Blowhole & $\mathrm{AB}$ \\
Apex of melon to Posterior insertion of dorsal fin & $\mathrm{AP}$ \\
Apex of melon to Anterior insertion of dorsal fin & $\mathrm{AA}$ \\
Blowhole to Anterior insertion of dorsal fin & $\mathrm{BA}$ \\
Dorsal fin Height & $\mathrm{DH}$ \\
Dorsal fin Width & $\mathrm{DW}$ \\
Blowhole to Posterior insertion of dorsal fin & $\mathrm{BP}^{\mathrm{a}}$ \\
\hline
\end{tabular}

${ }^{\mathrm{a}} \mathrm{BP}$ was a calculated value where $\mathrm{BP}=(\mathrm{BA}+\mathrm{DW})$.

each measurement counted, and the ratios (Table 2) calculated. Dorsal fin reference lines were adapted from Durban and Parsons (2006).

\section{Pigmentation}

We evaluated each image for the presence of four pigmentation patterns (Fig. 4): melon patch, postorbital eye blaze, cape, and saddle patch. The melon patch is an area of pigmentation located on the top of the head, extending forward from the blowhole, and has not been previously described in the literature as a species identifying characteristic. The highly variable postorbital eye blaze (i.e., eye stripe or eye patch) has been described and analyzed for LFPWs (Bloch et al. 1993b) and SFPWs (Yonekura et al. 1980, Kasuya et al. 1988); it ranges from an indistinct stripe extending just above the eye to a conspicuous, bright, thick stripe extending all the way to the dorsal side of the back and blending into the cape (Kasuya et al. 1988, Bloch et al. 1993b). The cape is an area of pigmentation that extends from the eye blaze to the saddle patch, which is located posterior to the dorsal fin (Jefferson et al. 2008). Capes are highly variable and can range from a subtle distinction from the

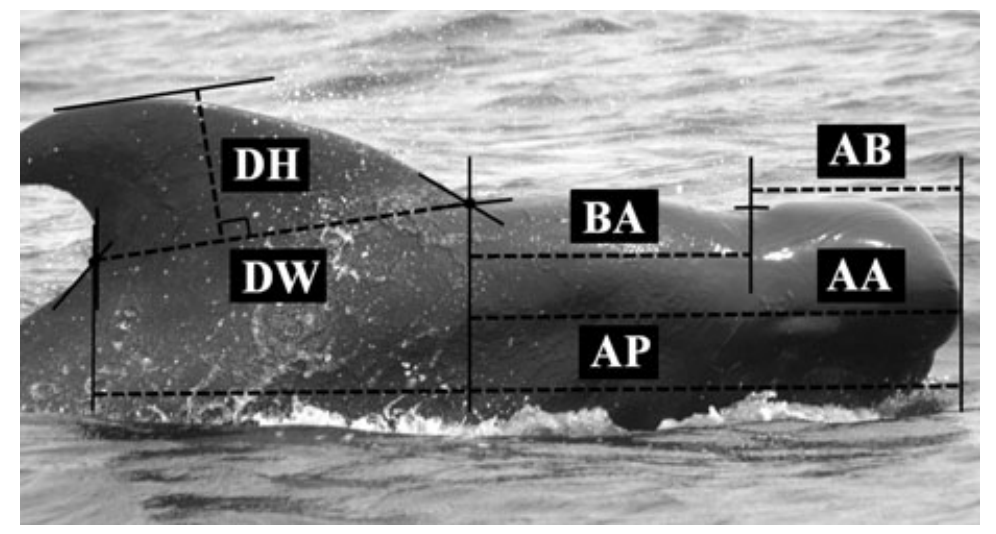

Figure 3. Reference lines (solid) used to define the six morphometric features and measurements collected (dotted) on an image of a free-ranging northwest Atlantic pilot whale used for species discrimination. 
Table 2. Eleven combinations of ratios from six morphological features used to build and test discrimination functions for species identification. See Table 1 for definition of each morphological feature.

\begin{tabular}{llll}
\hline \hline \multicolumn{3}{c}{ Morphometric ratios } \\
\hline AA/AP & AB/BP & BA/AP & DW/AA \\
AB/BA & AB/AP & DH/BA & DW/BA \\
AB/AA & BA/AA & DH/DW & \\
\hline
\end{tabular}

overall dark pigmentation to a highly conspicuous distinction that covers the area below, and at times, including the dorsal fin. The saddle patch is one of the most common pigmentation patterns analyzed, along with the eye blaze (Yonekura et al. 1980, Kasuya et al. 1988, Bloch et al. 1993b). The saddle patch is located posterior to the dorsal fin and can range from a sparse, localized patch directly behind the dorsal fin to a conspicuous patch extending from the cape down the length of the dorsal side of the caudal peduncle.

Pigmentation images were culled to remove poor images resulting from glare, exposure, water splashes, and low-lighting conditions. Pigmentation in a body region was scored as: present (1), absent (0), or undecided (U). Any presence of pigmentation (irrespective of the level of intensity) was scored as present, except for cases of white spots which were assumed to be scars (Auger-Méthé and Whitehead 2007). If we could not provide a definitive answer for presence/absence (e.g., when the region photographed was too narrow to detect patterns in contrasting pigmentation or the photograph was poorly exposed), the image was designated as undecided and was excluded from the pigmentation analysis.

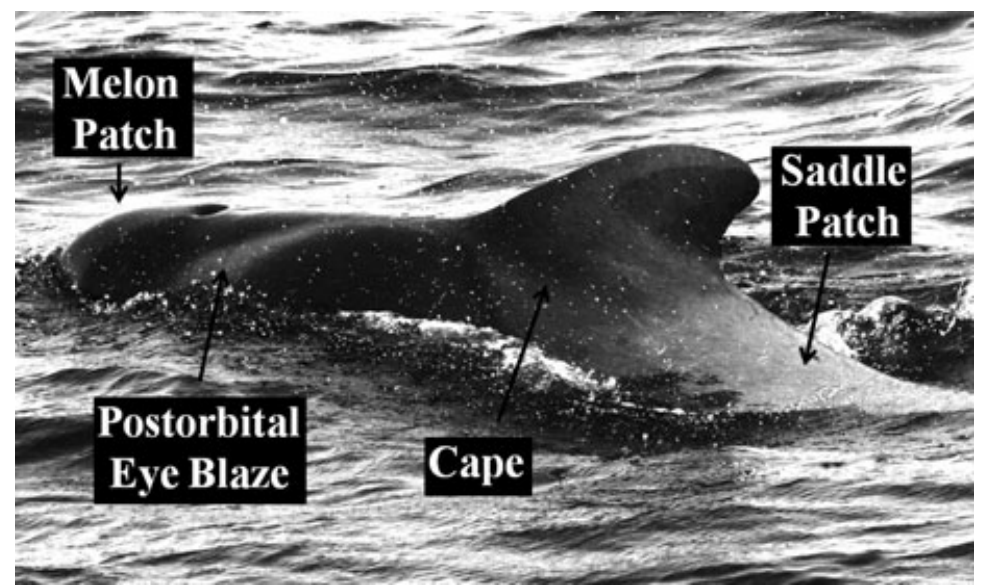

Figure 4. The four categories analyzed for pigmentation. The pilot whale in this example displays the presence of pigmentation in all four areas: melon patch, postorbital eye blaze, cape, and saddle patch. 
Analysis

Data treatment -Allometric growth rate (Yonekura et al. 1980, Bloch et al. 1993a) and sexual dimorphism (Yonekura et al. 1980) are two important characteristics that have to be considered in morphometric analyses. Some previous studies accounted for sexual dimorphism through separate analyses of males and females (Sergeant 1962a, b; Yonekura et al. 1980; Bloch and Lastein 1993; Bloch et al. 1993a, b; Kasuya and Tai 1993). However, because our data were collected at sea from live animals and only large adult males could be accurately identified, we incorporated into the statistical analyses consideration of variation due to both allometric growth and sexual dimorphism by including the three-level size-class covariate (large, medium, and small). To avoid statistical complications such as unequal sample sizes among candidate models and uncertainties of imputed values (Quinn and Keough 2002), we eliminated all individuals with any missing measurements.

Testing for pseudoreplication-Pilot whales are typically observed in groups where multiple groups can be in close proximity to one another. It has been shown that members within a group (Amos et al. 1993a, b), and perhaps groups within an aggregation (Connor et al. 2000, Ottensmeyer and Whitehead 2003), are closely related genetically. We tested the potential for increased correlation of measurements due to relatedness (pseudoreplication) through a mixed model analysis (Hurlbert 1984). The ratios (Table 2) were independently used as response variables in the mixed models that treated species (identified by genetics or close associations with genetically sampled animals), size class, and their interaction as fixed categorical predictors. Sampling hierarchies of aggregation, groups within an aggregation, and individuals (residual) were treated as random factors. Calculations were accomplished using R statistical analysis software (Version 2.7.1; Libraries lme4 Bates 2008, and lattice Sarkar 2008; R Development Core Team 2009). Goodness of fits of the models were evaluated using the Akaike Information Criteria (AIC). The best fitting model had the lowest AIC value and models within two units of that best fitting model were all considered to have substantial support (Burnham and Anderson 2002).

Discriminant functions - Data were partitioned into two sets, a training set and a validation set. The training set included all measurements from individuals that did not have an associated genetic sample, but were photographed within the same group for which individuals were biopsied and species identity confirmed. The validation set included measurements only from individuals that had their species identity determined from genetic analysis.

We constructed discrimination functions in the form of logistic regressions (Version 2.7.1; Libraries lme4 Bates 2008, and lattice Sarkar 2008; R Development Core Team 2009) using combinations of measurement ratios. Logistic regressions predicted the probability that an individual was an SFPW given a combination of predictors. We examined the combined training and validation sets for evidence of collinearity in the data prior to producing the logistic regression models. Although strong correlations between predictors may not reduce the predictive value of regression models, they often inflate the standard errors of the estimates of model coefficients and undermine the statistical significance of an independent variable (Menard 1995, Tabachnick and Fidell 1996, Allen 1997, Hosmer and Lemeshow 2000, Quinn and Keough 2002).

Parameter estimates for the logistic regression models were calculated for the training data set only. Models were selected using AIC and the top model was selected for further analysis. 
To assess the predictive power, we used the selected model to predict species identity of individuals in the validation set whose species identity was characterized from genetics. Misclassification rates for the validation set (assuming genetic identity was true) were calculated using the following cutpoints:

$$
P_{\mathrm{SFPW}} \geq 0.5 \text { and } P_{\mathrm{LFPW}}<0.5,
$$

where $P$ is the predicted value from a logistic regression.

Receiver operating characteristic (ROC) - We examined the discriminatory ability of the selected model using the area under the curve (AUC) of an ROC plot (Hosmer and Lemeshow 2000). The AUC is an index of prediction accuracy, which ranges from 0.5 when the ROC curve corresponds to random chance to 1.0 for a perfect discriminator (Fawcett 2006). Discrimination performance was rated as poor, acceptable, excellent, or outstanding when found to be in the ranges $0.5-0.7,0.7-0.8,0.8-0.9$, and $>0.9$, respectively (González-Suárez and Gerber 2008).

Pigmentation - Pigmentation patterns on an animal were described by calculating proportions of presence/absence of white pigmentation in each of four pigmentation regions based on visual scoring. Differences in these patterns between the two species were then explored.

In this study, only the lead author (BKR) scored the data set. Presence/absence of pigmentation is a qualitative judgment based on a scorer's interpretation of the image. To determine whether protocol interpretations would vary significantly among scorers, we tested scorer performance. We selected four people with cetacean photo-identification experience to score 40 images (10 images for each category). Images were cropped to show only the region of the body being scored. The scorers were provided the same training and a protocol reference document to use while scoring images. Variance of scoring was analyzed by comparing the number of scores in agreement with scores from BKR for each category:

$$
\frac{(\mathrm{Sc} 1+\mathrm{Sc} 2+\mathrm{Sc} 3+\mathrm{Sc} 4) / 4}{\mathrm{BKR}} \times 100 \% \text {. }
$$

RESULTS

Morphometric Analyses

Sample size-Two hundred and forty-four genetic samples were collected during 2004-2007 (Fig. 5). There were 178 samples collected from 78 groups of SFPWs (range $=1-11$, median $=2$ ) and 66 samples collected from 29 groups of LFPWs (range $=1-7$, median $=2$ ). Based on species determinations of genetic samples, both SFPWs and LFPWs were found along the shelf break/slope regions, but only SFPW were found in the deep, offshore waters $(>2,500 \mathrm{~m})$. There were 165 genetic samples not associated with a set of images that qualified for use in the morphometric analyses. However, all species classifications from biopsies were used because they provided species identification of groups from which individuals without a genetic sample were photographed. Additionally, these classifications provided strong support for the assumption that animals within a single aggregation were of the same species because no evidence to the contrary was detected among the 244 determinations. Eleven measurement ratios (Table 2) were calculated for the 79 individuals in the 


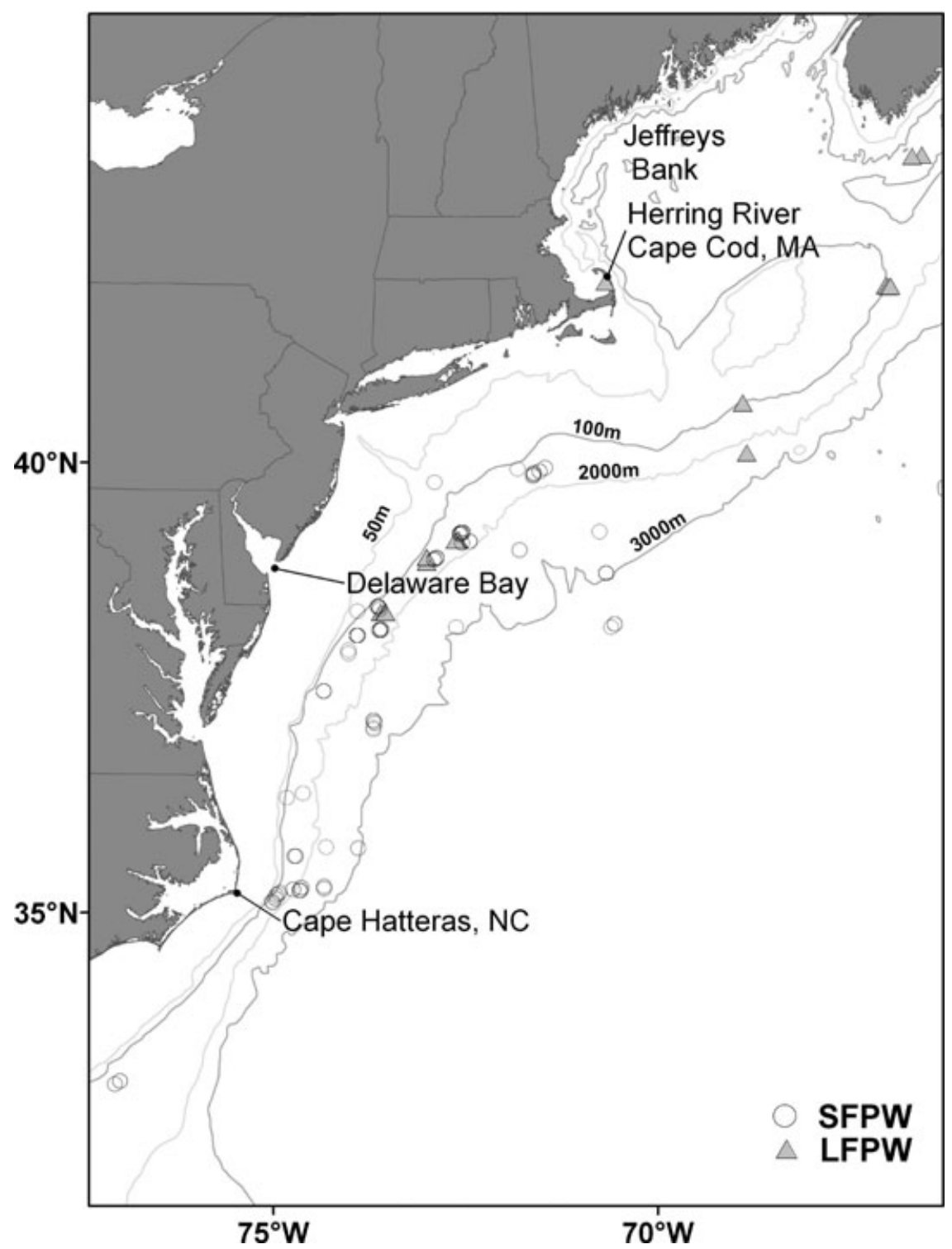

Figure 5. Location of genetic samples collected during the years 2004-2007. Not all genetic samples depicted here were coincident to a photograph for morphometric analysis due to missing measurement values or lack of photographs. Symbols overlap when multiple samples were collected in the same geographic location.

validation set. Training and validation sets were combined for pigmentation analyses $(n=949)$ (Table 3).

Pseudoreplication test-Mixed-effect analysis for the 11 ratios tested showed no contribution to variance for higher groupings of samples (the random factors of aggregation and group, Table 4). With two exceptions, the best model for 
Table 3. Sample sizes of northwest Atlantic long-finned (LFPW) and short-finned (SFPW) pilot whales for the morphometric and pigmentation analyses. Training set contains the photographs of individuals that do not have an associated genetic sample but are identified because of their association with genetically sampled individuals. Validation set contains the photographs of individuals that have been collected coincident with a genetic sample.

\begin{tabular}{lccc}
\hline \hline & \multicolumn{2}{c}{ Morphometrics } & \\
\cline { 2 - 3 } Species & Training set & Validation set & Pigmentation \\
\hline LFPW & 88 & 7 & 293 \\
SFPW & 293 & 72 & 656 \\
Total & 381 & 79 & 949 \\
\hline
\end{tabular}

measurement ratios was a simple additive model with species and size as predictors and a single random term (sample error). In the cases of DW/BA and DH/BA, the best fit model indicated inconsistency among size classes between species and so included an interaction term. The ratio DW/AA was the only variable with some apparent hierarchical structuring among samples. However, variances for the random effects were less than one half of the residual which did not provide strong support for hierarchical structuring. For all measurement ratios, fixed factors species and size were strong predictors $(F$-test, $P<0.05)$. These mixed model results indicate no presence of pseudoreplication; these measurement ratios, when considered in conjunction with an individual's size, might have strong discriminatory power in distinguishing the species.

Table 4. Akaike Information Criteria (AIC) results from mixed models on the 11 morphometric ratios used to investigate for pseudoreplication.

\begin{tabular}{|c|c|c|c|c|c|c|}
\hline \multirow[b]{2}{*}{ Variable } & \multicolumn{6}{|c|}{ Mixed-effect models } \\
\hline & $\begin{array}{l}\text { Species }{ }^{*} \text { size } \\
\text { +aggregation } \\
\quad \text { +group: } \\
\text { aggregation }\end{array}$ & $\begin{array}{l}\text { Species * size } \\
\text { +aggregation }\end{array}$ & $\begin{array}{l}\text { Species * } \\
\text { size }\end{array}$ & $\begin{array}{l}\text { Species+size } \\
\text { +aggregation } \\
\text { +group: } \\
\text { aggregation }\end{array}$ & $\begin{array}{l}\text { Species+size } \\
\text { +aggregation }\end{array}$ & $\begin{array}{c}\text { Species } \\
+ \text { size }\end{array}$ \\
\hline $\mathrm{BA} / \mathrm{AA}$ & $-1,732$ & $-1,731$ & $-1,778$ & $-1,749$ & $-1,748$ & $-1,780$ \\
\hline $\mathrm{DH} / \mathrm{DW}$ & $-1,450$ & $-1,447$ & $-1,492$ & $-1,463$ & $-1,461$ & $-1,493$ \\
\hline $\mathrm{DW} / \mathrm{BA}$ & -954 & -954 & -976 & -661 & -626 & -642 \\
\hline $\mathrm{AB} / \mathrm{BA}$ & -941 & -941 & -975 & -953 & -953 & -975 \\
\hline $\mathrm{AB} / \mathrm{AA}$ & $-1,786$ & $-1,786$ & $-1,831$ & $-1,802$ & $-1,802$ & $-1,833$ \\
\hline $\mathrm{DW} / \mathrm{AA}$ & $-1,284$ & $-1,257$ & $-1,289$ & $-1,297$ & $-1,270$ & $-1,290$ \\
\hline $\mathrm{AB} / \mathrm{BP}$ & $-1,651$ & $-1,653$ & $-1,704$ & $-1,667$ & $-1,669$ & $-1,705$ \\
\hline $\mathrm{AA} / \mathrm{AP}$ & $-2,134$ & $-2,108$ & $-2,151$ & $-2,151$ & $-2,126$ & $-2,153$ \\
\hline $\mathrm{DH} / \mathrm{BA}$ & $-1,311$ & $-1,302$ & $-1,346$ & $-1,321$ & $-1,312$ & $-1,344$ \\
\hline $\mathrm{AB} / \mathrm{AP}$ & $-2,225$ & $-2,227$ & $-2,285$ & $-2,243$ & $-2,245$ & $-2,287$ \\
\hline $\mathrm{BA} / \mathrm{AP}$ & $-1,861$ & $-1,849$ & $-1,883$ & $-1,880$ & -1.866 & -1.886 \\
\hline
\end{tabular}

Size $=$ animal size class $;\left(^{*}\right)=$ additive plus interaction effect; $(:)=$ nested effect; aggregation $=$ sighting where an individual was found; group $=$ specific group where an individual was photographed. 
Table 5. Seven highly correlated pairwise ratios that were excluded from the logistic regression analysis. Correlation coefficients are shown in parentheses.

\begin{tabular}{ll}
\hline \hline & Pairwise predictors \\
\hline $\mathrm{AA} / \mathrm{AP}+\mathrm{DW} / \mathrm{AA}(-0.99)$ & \\
$\mathrm{AA} / \mathrm{AP}+\mathrm{DW} / \mathrm{BA}(0.91)$ & $\mathrm{AB} / \mathrm{BP}+\mathrm{BA} / \mathrm{AA}(-0.81)$ \\
$\mathrm{AB} / \mathrm{BA}+\mathrm{AB} / \mathrm{BP}(0.80)$ & $\mathrm{DW} / \mathrm{BA}+\mathrm{DW} / \mathrm{BA}(0.82)$ \\
$\mathrm{AB} / \mathrm{BA}+\mathrm{BA} / \mathrm{AA}(0.80)$ & \\
\hline
\end{tabular}

Discriminant functions - We excluded models from the analysis containing any of seven pairs of ratios with a correlation value of 0.8 or greater (Table 5). This left a total of 94 candidate models that were analyzed using logistic regression analysis. There were five models with a $\triangle \mathrm{AIC}<2$ from the best model (Table 6). The predictors from the model with the smallest AIC were: AB/BA, DH/DW, DW/BA. When looking at the top six models, DH/DW and DW/BA were present in all models. The additional parameters were simply combinations of the same critical area: apex of melon to the dorsal fin. Including additional models did not increase the number of morphometric characters; therefore, only the first model was further investigated.

Using the top model from the logistic regression analysis, the discrimination function equation $( \pm \mathrm{SE})$ used to predict species identification is:

$$
P_{\text {SFPW }}=\exp (f) / 1+\exp (f)
$$

where $(f=$ function $)$

$$
\begin{aligned}
f= & -63.719( \pm 10.7)(\text { Large })+3.104( \pm 1.4)(\text { Medium }) \\
& +6.432( \pm 1.8)(\text { Small })+15.897( \pm 6.0)(\mathrm{AB} / \mathrm{BA}) \\
& +46.253( \pm 9.4)(\mathrm{DH} / \mathrm{DW})+44.126( \pm 8.7)(\mathrm{DW} / \mathrm{BA}) .
\end{aligned}
$$

Table 6. Summary of the top six logistic regression models for investigating northwest Atlantic pilot whale species prediction using the Akaike Information Criteria (AIC). The analysis was based on photographs from pilot whales $(n=381)$ assumed to be short-finned $(n=293)$ and long-finned $(n=88)$ based on their association with genetically sampled individuals. A low AIC indicates a better fit of the model to the data. The top model was selected to test the model's predictive power on the validation set. $k=$ parameters; $\Delta_{i}=$ AIC - min AIC.

\begin{tabular}{lccc}
\hline \hline Model & $k$ & AIC & $\Delta_{i}$ \\
\hline Size + AB/BA + DH/DW + DW/BA & 4 & 78.184 & 0 \\
Size + BA/AA + DH/DW + DW/BA & 4 & 78.374 & 0.19 \\
Size + AB/AA + DH/DW + DW/BA & 4 & 78.651 & 0.47 \\
Size + AB/BP + DH/DW + DW/BA & 4 & 79.727 & 1.54 \\
Size + BA/AA + DH/DW + DW/BA & 4 & 79.908 & 1.72 \\
Size + AB/BA + AB/BP + DH/DW + DW/BA & 5 & 80.182 & 2.00 \\
\hline
\end{tabular}



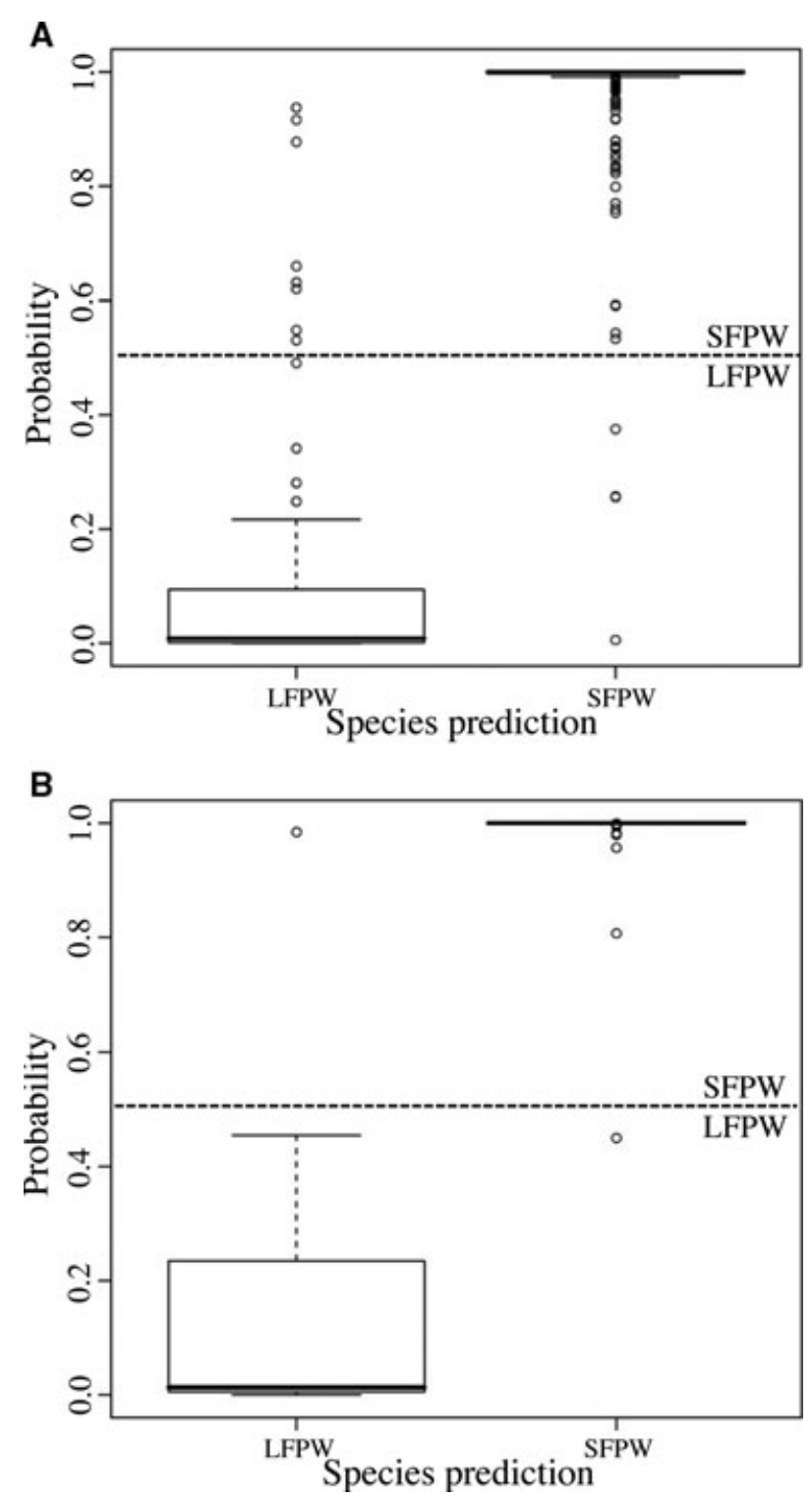

Figure 6. Boxplots of classification performance for the top model from (A) the training set and (B) the validation set. Note: $P_{\text {SFWP }} \geq 0.5 ; P_{\text {LFPW }}<0.5$, where $P$ is the predicted value from a logistic regression. $x$-axis: LFPW (0) and SFPW (1); $y$-axis: the probability of species prediction between 0 and 1 .

The overall classification error rate on the training set (a measure of fit) for this logistic regression was 3.4\%, resulting from 5 of 293 misclassified SFPWs and 8 of 88 LFPWs. The overall classification error rate for the validation set (a measure of the model's predictive power) was $2.5 \%$, resulting from 1 of 72 misclassified SFPWs and 1 of 7 misclassified LFPWs (Fig. 6) 


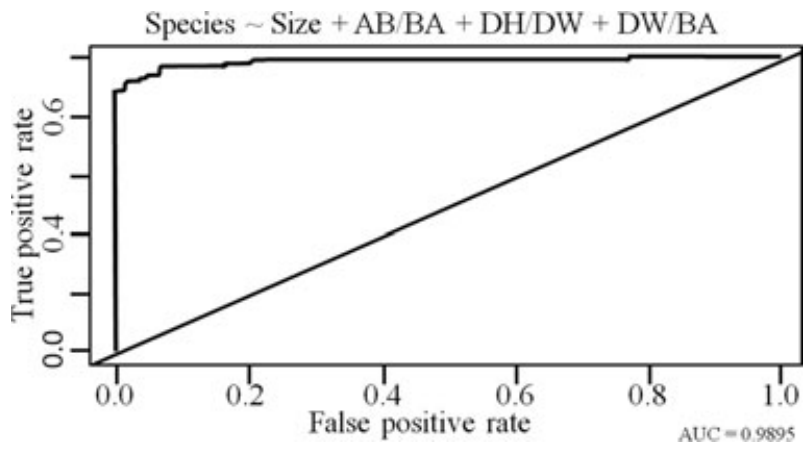

Figure 7. Receiver operating characteristic (ROC) curve analysis for the top discrimination model that differentiates between northwest Atlantic SFPWs and LFPWs.

ROC curve - The top model produced an AUC value of 0.99 (Fig. 7). Therefore, 99\% of the time this model correctly discriminated between SFPWs and LFPWs based on the variables: size, $\mathrm{AB} / \mathrm{BA}, \mathrm{DH} / \mathrm{DW}$, and DW/BA.

\section{Pigmentation Analyses}

Scorer performance test-There was a high correspondence in performance test results among the experienced pigment scorers (Table 7). However, there were fairly large differences between scorers that were with and without pilot whale photoidentification experience (Table 7).

Pigmentation patterns - All four pigmentation characters (melon patch, postorbital eye blaze, cape, and saddle patch) were present in $100 \%$ of the SFPWs sampled ( $n=$ 656). Melon patch, blaze, and saddle patch were present in $6 \%, 68 \%$, and $50 \%$ of LFPWs $(n=293)$, respectively; the cape was completely absent (Table 8$)$. Because the cape was absent, it was excluded from additional analyses. Of LFPWs with the presence or absence evaluated for all three patterns $(n=70), 23 \%(n=16)$ had a saddle only, $24 \%(n=17)$ had a blaze and saddle and additional combinations of the three patterns were $7 \%$ or less. Only $2.9 \%(n=2)$ had all three patterns present (Table 9).

Table 7. Results from the pigmentation scorer performance test. The abbreviations (Sc1, Sc2, Sc3, Sc4, BKR) represent individual scorers. Test 1 was conducted with four cetacean biologists. Test 2 was conducted with two of the four cetacean biologists who were familiar with pigmentation patterns on northwest Atlantic pilot whales.

\begin{tabular}{|c|c|c|c|c|}
\hline \multirow{2}{*}{$\begin{array}{l}\text { Pigmentation } \\
\text { pattern }\end{array}$} & $\begin{array}{c}\text { Test 1: } \\
(\mathrm{Sc} 1+\mathrm{Sc} 2+\mathrm{Sc} 3+\mathrm{Sc} 4) / 4 \\
\end{array}$ & \multirow[b]{2}{*}{ Concurrence } & \multirow{2}{*}{$\begin{array}{c}\text { Test 2: } \\
(\mathrm{Sc} 1+\mathrm{Sc} 2) / 2 \\
\mathrm{BKR}\end{array}$} & \multirow[b]{2}{*}{ Concurrence } \\
\hline & BKR & & & \\
\hline Melon patch & $9.5 / 10$ & $95 \%$ & $10 / 10$ & $100 \%$ \\
\hline Blaze & $9.5 / 10$ & $95 \%$ & $10 / 10$ & $100 \%$ \\
\hline Cape & $7 / 10$ & $70 \%$ & $8 / 10$ & $80 \%$ \\
\hline Saddle patch & $8.25 / 10$ & $83 \%$ & $9.5 / 10$ & $95 \%$ \\
\hline
\end{tabular}


Table 8. The distribution of the four pigmentation patterns in free-ranging northwest Atlantic LFPWs and SFPWs. $n=$ sample size of animals evaluated for each pattern.

\begin{tabular}{lcccc}
\hline \hline & \multicolumn{2}{c}{ LFPW } & \multicolumn{2}{c}{ SFPW } \\
\cline { 2 - 3 } Pattern & $n$ & $\%$ presence & & $n$ \\
\hline Melon patch & 95 & 6.4 & 544 & $\%$ presence \\
Blaze & 122 & 68 & 595 & 100 \\
Cape & 205 & 0 & 591 & 100 \\
Saddle patch & 264 & 50 & 607 & 100 \\
\hline
\end{tabular}

Table 9. Occurrence of the three pigmentation patterns in free-ranging northwest Atlantic LFPWs. $n=$ number of LFPWs (total $=70$ ) expressing the pattern.

\begin{tabular}{lrc}
\hline \hline Pattern & $n$ & $\%$ presence \\
\hline Melon patch only & 0 & 0 \\
Blaze only & 0 & 0 \\
Saddle patch only & 16 & 23 \\
Melon patch and blaze only & 5 & 7 \\
Melon patch and saddle only & 0 & 0 \\
Blaze and saddle patch only & 17 & 24 \\
Melon patch, blaze, and saddle patch & 2 & 2.9 \\
\hline
\end{tabular}

\section{DISCUSSION}

Given the transient structure of groups and our frequent inability to distinguish separate groups within an aggregation, a lack of evidence for hierarchical structuring among samples (pseudoreplication) was not surprising. Whether this was the result of a more random mixing of individuals than thought a priori, or the lack of influence of relatedness on the ratios of measurements cannot be determined, but the end result was a simplification of considerations necessary for discriminating these two species during the summer in the northwest Atlantic.

\section{Morphometrics}

Initial opinions on morphological differences by biologists studying these populations were that SFPWs appear short and compact, whereas LFPWs are long and sleek in comparison. Cope (1876) suggested that the dorsal fin was placed further up the back on SFPWs, but attempts to verify this statement were inconclusive (Sergeant 1962a, Yonekura et al. 1980). The three measurement ratios, AB/BA, BA/AA, and $\mathrm{AB} / \mathrm{AA}$ are combinations of the three areas that might quantitatively investigate this opinion. The short and stocky perception likely comes from the smaller proportion of AA length made up by the distance from blowhole to the anterior insertion of the dorsal fin in SFPWs and differences in skull morphology (Olson and Reilly 2002). These differences anterior to the dorsal fin provided some of the discriminatory power that we observed.

In an attempt to increase the variety of characters that could be captured in an image, and thereby increase the number of images for analysis that could be used, 
we considered the top three candidate logistic regression models (Table 6). However, the three best models all required some combination of the same core measurements. Therefore, reliable species identification based on relative measurements from images requires that the entire region from the apex of melon to the posterior insertion of the dorsal fin must be captured.

Investigation of the misclassified animals from the training and validation sets showed that of the 16 misclassified animals, images of 12 animals deviated from a desirable profile (see Fig. 3 for ideal). The animal was either sitting low in the water, water splashes were covering the apex of the melon or the animal was flexing its torso. Four images provided ideal profile photographs but misclassifications could not be explained. Thus, care should be taken when choosing the images to estimate the measurements. More restrictive quality grading of whale profiles would reduce the likelihood of such misclassifications occurring.

\section{Pigmentation}

While pigmentation is highly variable between populations of pilot whales globally (Yonekura et al. 1980, Kasuya et al. 1988, Bloch et al. 1993b, Jefferson et al. 2008), overall pigmentation variation between LFPWs and SFPWs observed within this study area was distinct enough to discriminate between the two species. Qualitative opinion from biologists studying these populations suggests that SFPWs have an overall lighter appearance than LFPWs. The consistent presentation of the overall pigmentation pattern, a melon patch and a continuous pigmentation pattern starting from the eye to the cape to the saddle, supports this observation (Fig. 8A), In addition to the absence of the melon patch, blaze, and saddle patch at times, the distinguishing features of the LFPWs were the lack of cape and the differences in the saddle patch shape in relation to SFPWs (Fig. 8B). The saddle patch of LFPWs, if present, is a patch with a distinct boundary located posterior to the dorsal fin. In contrast, the saddle patch of SFPWs, always present, does not have a defined boundary and extends from the cape posterior to the dorsal fin and down the dorsal side of the caudal peduncle. Intensity and prominence of each pigmentation pattern was highly variable for the two species. Intensity ranged from barely discernable to striking. The melon patch extent was highly variable, extending directly down from the blowhole, encompassing the entire melon region or extending forward of the blowhole and only on the apex. Regardless of the variations within each species, pigmentation proved to be a strong discriminator for identification; however, we do not advise applying pigment tests to stranded animals because these pigmentation patterns may be quickly lost (Yonekura et al. 1980).

In our simple test of observer effect on detecting pigmentation patterns in pilot whale images, there were disagreements with BKR's scores for a few animals. Potential explanations for discrepancies on the pigmentation analysis test were apparent after interviewing participants. We realized that the cape, in particular, was difficult to discern without having an image of the entire animal to reference. For this test, images were cropped down to emphasize the region that was to be scored. During training, it was clear that scorers were unfamiliar with the cape pattern on pilot whales and this was their first introduction. This most likely caused uncertainty in responses about cape presence when scorers examined the cropped images. Other causes for misinterpretation were water splashes and areas of glare. In addition, any evidence of pigmentation in the region was scored as present by BKR. In a few 


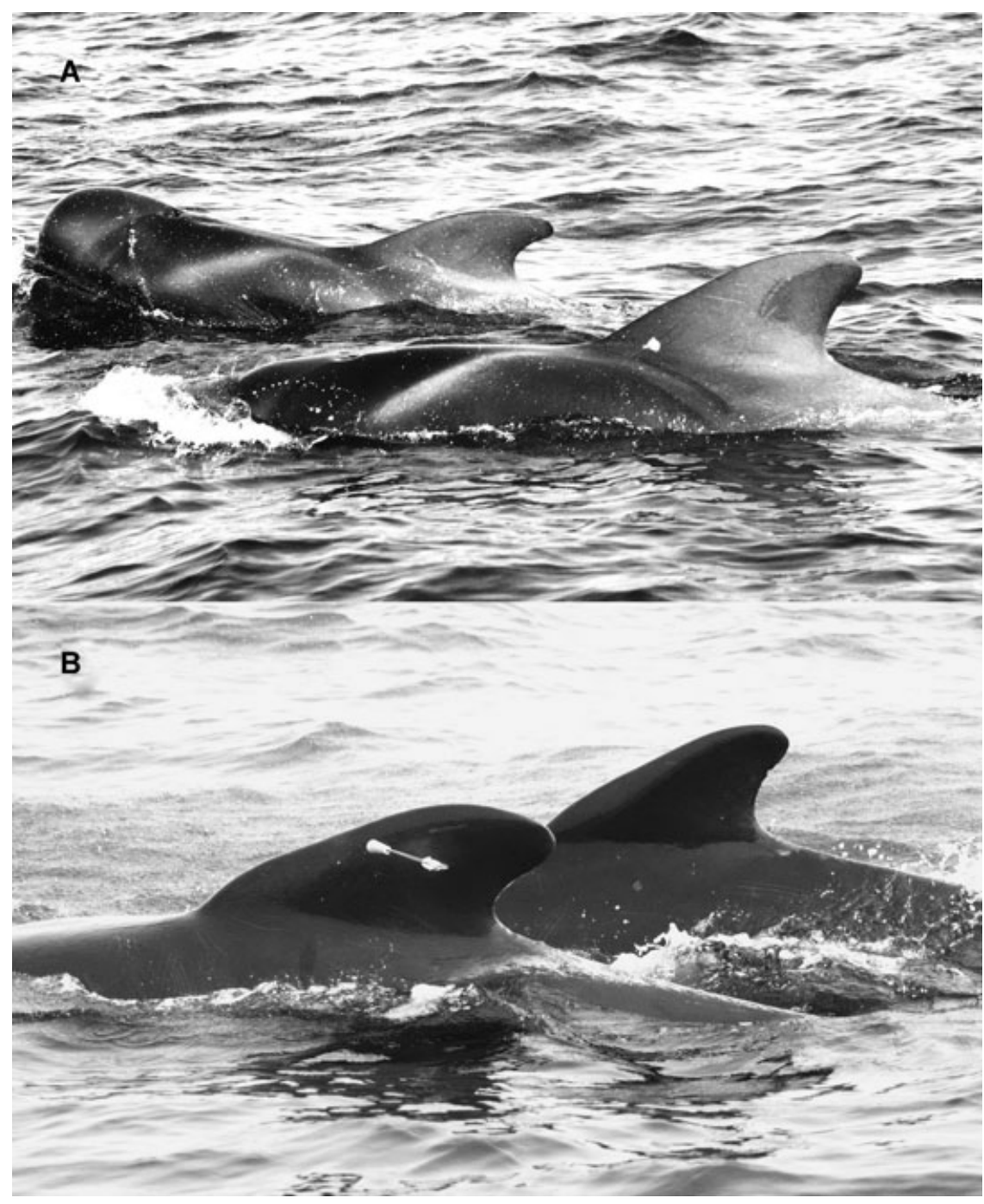

Figure 8. (A) Pigmentation characteristics on two northwest Atlantic SFPWs: melon patch, blaze, cape, and saddle patch extending from the cape down the dorsal caudal peduncle. (B) Northwest Atlantic LFPWs displaying both the absence of the cape and two common saddle patch scenarios: the absence of the saddle patch (back animal) and the saddle patch with a distinct boundary located just posterior to the dorsal fin (front animal).

instances, sparse pigmentation was a source of interpretation error. Finally, including an "undecided" category increased the error in agreement due to frequent use by some scorers. Results showed that, overall, reproducibility in the scoring process was good $(\geq 80 \%)$ but accuracy of analysis relied on the experience of the scorer and clear interpretation of the protocols. 


\section{Recommendations}

We have designed two procedures to identify pilot whales at sea in the northwest Atlantic under varying field conditions. If a sighting event occurs during sufficient daylight and the lighting is such that pigmentation contrast is easily discernable (e.g., sunny conditions and minimal glare) and capturing acceptable images for morphometric discrimination is not possible, analysis of the pigmentation is likely sufficient for determining species. However, during times with difficult lighting conditions (e.g., glare, sunrise, sunset, or overcast), a morphometric analysis should be applied. To achieve the most accurate species identification, the two approaches should be used together to provide multiple pieces of evidence for determining the species identity.

To capture the overall representation of individuals within a sighting event, as many individuals as is possible should be photographed. We also recommend that effort be made to obtain images that are as close to protocol as is possible (i.e., perpendicular, close range, and minimal glare) with a high-resolution camera. Discerning saddle patches and capes can be difficult depending on the position of the animals in the water. Therefore, the complete surfacing of the animal should be photographed. This will produce documentation of all relevant body regions.

\section{Management Implementations}

Until now, many cetacean biologists thought that pilot whales shared similar morphological traits and that reliable determinations of species could not be made at sea in areas where both species are found. In this study, image utility was explored, image protocols for analysis were defined, and results showed that a species designation for free-ranging northwest Atlantic pilot whales was quite reliable when implementing a simple, inexpensive method. This method can easily be incorporated into future east coast cetacean abundance surveys which could then result in separate abundance estimates of SFPWs and LFPWs.

\section{ACKNOWLEDGMENTS}

Research was conducted in partial fulfillment of a Master of Science in biology at the University of Massachusetts, Boston. We would like to thank Solange Brault and John Ebersole for their reviews of this work and early versions of the manuscript. We thank Brendan Hurley for his assistance on data collection and analysis. Species determinations of genetic samples were conducted under the direction of Patricia Rosel, NMFS, Lafayette, Louisiana. We thank the many people involved in data acquisition and support which made this project a success: John Nicolas, Fred Wenzel, Brett Hayward, Misty Niemeyer, Tim Cole, Peter Duley, Cynthia Christman, Allison Henry, Marie Martin, Erin LaBrecque, Tonya Wimmer, Annie Douglas, Laura Morse, Kelly Cunningham, Anthony Martinez, Stephen Claussen, Melody Baran, Carrie Sinclair, Grisel Rodriguez-Ferrer, Jesse Wicker, Kevin Barry, Anna Sellas, Carol Fairfield, Leslie Burdett Hart, Kim Urian, Andy Read, and the officers and crew from NOAA ships Delaware II and Gordon Gunter. We thank Michael Moore, Andrea Bogomolni, Katie Touhey Moore, and the IFAW Marine Mammal Rescue and Research for access to and assistance with the stranded pilot whale. Thanks to Phillip Clapham and Lance Garrison for project support. Finally, we thank Debra Palka, Alexandre Zerbini, Robert Brownell, Robin Baird, Michael Simpkins, Gary Duker, and Christine Baier for their constructive comments on this manuscript. Research was conducted under NMFS Scientific Permit Nos. 779-1633 and 775-1600. The findings and conclusions in this paper are those of the authors and do not necessarily represent the views of the National Marine Fisheries Service. 


\section{Literature Cited}

Allen, M. P. 1997. Understanding regression analysis. Plenum Press, New York, NY.

Amos, B., J. A. Barrett, D. R. Bancroft, T. M. O. Majures, D. Bloch, G. Desportes and G. A. Dover. 1993a. A review of molecular evidence relating to social organization and breeding system in the long-finned pilot whale. Report of the International Whaling Commission (Special Issue 14):219-231.

Amos, B., C. Schlötterer and D. Tautz. 1993b. Social structure of pilot whales revealed by analytical DNA profiling. Science 260:670-672.

Auger-Méthé, M., and H. Whitehead. 2007. The use of natural markings in studies of long-finned pilot whales (Globicephala melas). Marine Mammal Science 23:77-93.

Baird, R. W., and P. J. Stacey. 1988. Variation in saddle patch pigmentation in populations of killer whales (Orcinus orca) from British Colombia, Alaska and Washington State. Candian Journal of Zoology 66:2582-2585.

Bloch, D., and L. Lastein. 1993. Morphometric segregation of long-finned pilot whales in eastern and western North Atlantic. Ophelia 38:55-68.

Bloch, D., C. Lockyer and M. Zachariassen. 1993a. Age and growth parameters of the long-finned pilot whale off the Faroe Islands. Report of the International Whaling Commission (Special Issue 14):163-207.

Bloch, D., M. Zachariassen and P. Zachariassen. 1993b. Some external characters of the longfinned pilot whale off the Faroe Islands and a comparison with the short-finned pilot whale. Report of the International Whaling Commission (Special Issue 14):117-135.

Burnham, K. P., and D. R. Anderson. 2002. Model selection and inference: A practical information-theoretic approach. 2nd edition. Springer-Verlag, New York, NY.

Connor, R. C., A. J. Read and R. Wrangham. 2000. Male reproductive strategies and social bonds. Pages 247-269 in J. Mann, R. C. Connor, P. L. Tyack and H. Whitehead, eds. Cetacean societies: Field studies of dolphins and whales. The University of Chicago Press, Chicago, IL.

Cope, E. D. 1876. Fourth contribution to the history of existing Cetacea. Proceedings of the Academy of Natural Science of Philadelphia 28:129-139.

Davies, J. L. 1960. The southern form of the pilot whale. Journal of Mammalogy 41:29-34.

Durban, J. W., and K. M. Parsons. 2006. Laser-metrics of free-ranging killer whales. Marine Mammal Science 22:735-743.

Evans, W. E., A. V. Yablokov and A. E. Bowles. 1982. Geographic variation in the color pattern of killer whales (Orcinus orca). Report of the International Whaling Commission 32:687-694.

Fawcett, T. 2006. An introduction to ROC analysis. Pattern Recognition Letters 27:861-874.

Gannon, D. P., A. J. Read, J. E. Craddock, K. M. Fristrup and J. R. Nicolas. 1997a. Feeding ecology of long-finned pilot whales Globicephala melas in the western North Atlantic. Marine Ecology Progress Series 148:1-10.

Gannon, D. P., A. J. Read, J. E. Craddock and J. G. Mead. 1997b. Stomach contents of long-finned pilot whales (Globicephala melas) stranded on the U.S. Mid-Atlantic coast. Marine Mammal Science 13:405-418.

Gaskin, D. E. 1982. The ecology of whales and dolphins. Heinemann Educational Books Ltd., London, U.K.

González-Suárez, M., and L. R. Gerber. 2008. Habitat preferences of California sea lions: Implications for conservation. Journal of Mammalogy 89:1521-1528.

Hain, J. H. W., M. A. M. Hyman, R. D. Kenney and H. E. Winn. 1985. The role of cetaceans in the shelf-edge region of the northeastern United States. Marine Fisheries Review 47:13-17.

Hamazaki, T. 2002. Spatiotemporal prediction models of cetacean habitats in the midwestern North Atlantic Ocean (from Cape Hatteras, North Carolina, U.S.A. to Nova Scotia, Canada). Marine Mammal Science 18:920-939.

Hosmer, D. W., and S. Lemeshow. 2000. Applied logistic regression. 2nd edition. Wiley, New York, NY. 
Hurlbert, S. H. 1984. Pseudoreplication and the design of ecological field experiments. Ecological Monographs 54:187-211.

ICES (International Council for the Exploration of the Sea). 1993. Report of the study group on long-finned pilot whales, Copenhagen, 30 August-3 September. Copenhagen, Denmark; ICES. C. M. 1993/N:5:29.

Jefferson, T. A., M. A. Webber and R. L. Pitman 2008. Marine mammals of the world: A comprehensive guide to their identification. Academic Press/Elsevier, London, U.K.

Kasuya, T., and S. Tai. 1993. Life history of short-finned pilot whale stocks off Japan and a description of the fishery. Report of the International Whaling Commission (Special Issue 14):439-472.

Kasuya, T., T. Miyashita and F. Katsamatsu. 1988. Segregation of two forms of short-finned pilot whales off the Pacific coast of Japan. Scientific Reports of the Whales Research Institute, Tokyo 39:77-90.

Koopman, H. N., and D. E. Gaskin. 1994. Individual and geographical variation in pigmentation patterns of the harbor porpoise, Phocoena phocoena (L.). Canadian Journal of Zoology 72:135-143.

Leatherwood, S., D. K. Caldwell and H. E. Winn. 1976. Whales, dolphins, and porpoises of the western North Atlantic. A guide to their identification. U.S. Department of Commerce, NOAA Technical Report NMFS Circular 396. 176 pp.

May-Collado, L., and I. Agnarsson. 2006. Cytochrome b and Bayesian inference of whale phylogeny. Molecular Phylogenetics and Evolution 38:344-354.

Mead, J. G. 1979. An analysis of cetacean strandings along the eastern coast of the United States. Pages 54-68 in J. R. Geraci and D. J. St. Aubin, eds. Biology of marine mammals: Insights through strandings. Marine Mammal Commission, Washington, DC

Menard, S. 1995. Applied logistic regression analysis. Sage Publications, Thousand Oaks, CA.

Olson, P. A., and S. B. Reilly. 2002. Pilot whales. Pages 898-903 in W. F. Perrin, B. Würsig and J. G. M. Thewissen, eds. Encyclopedia of marine mammals. Academic Press, London, U.K.

Oremus, M., R. Cales, M. L. Dalebout, et al. 2009. Worldwide mitochondrial DNA diversity and phylogeny of pilot whales (Globicephala spp.). Biological Journal of Linnean Society 98:729-744.

Ottensmeyer, C. A., and H. Whitehead. 2003. Behavioral evidence for social units in longfinned pilot whales. Canadian Journal of Zoology 81:1327-1338.

Payne, P. M., and D. W. Heinemann. 1993. The distribution of pilot whales (Globicephala spp.) in the shelf/shelf-edge and slope waters of the Northeastern United States, 1978-1988. Report of the International Whaling Commission (Special Issue 14):51-68.

Perrin, W. F. 1972. Color patterns of spinner porpoises (Stenella CR. S. longirostris) of the eastern Pacific and Hawaii, with comments on delphinid pigmentation. Fisheries Bulletin 70:983-1003.

Perryman, W. L., and M. S. Lynn. 1993. Identification of geographic forms of common dolphins (Delphinus delphis) from aerial photogrammetry. Marine Mammal Science 9:119_ 137.

Pitman, R. L., and P. Ensor. 2003. Three forms of killer whales (Orcinus orca) in Antarctic waters. Journal of Cetacean Research and Management 5:131-139.

Quinn, G. P., and M. J. Keough. 2002. Experimental designs and data analysis for biologists. Cambridge University Press, Cambridge, U.K.

Rayner, G. W. 1939. Globicephala leucosagmorpha, a new species of the genus Globicephala. Annals and Magazine of Natural History (Series 2) 4:543-544.

R Development Core Team. 2009. R: A language and environment for statistical computing. R Foundation for Statistical Computing, Vienna, Austria.

Rone, B. K. 2009. Discriminating between free-ranging long-finned (Globicephala melas) and short-finned (G. macrorbynchus) pilot whales off the east coast of the United States. M.S. thesis, University of Massachusetts, Boston, MA. 119 pp. 
Sergeant, D. E. 1962a. On the external characters of the blackfish of pilot whales (genus Globicephala). Journal of Mammalogy 43:395-413.

Sergeant, D. E. 1962b. The biology of the pilot whale or pothead, Globicephala melaena, in Newfoundland waters. Journal of the Fisheries Research Board of Canada 19: $1-84$.

Stacey, P. J., and R. W. Baird. 1993. Status of the short-finned pilot whale, Globicephala macrorbynchus, in Canada. The Canadian Field Naturalist 107:481-489.

Tabachnick, B., and L. Fidell. 1996. Using multivariate statistics. 3rd edition. Harper \& Row, New York, NY.

Wade, P. R., and R. Angliss. 1997. Report of the GAMMS workshop. April 3-5, 1996, Seattle, Washington. U.S. Department of Commerce, NOAA Technical Memorandum NMFS-OPR-12. 93 pp.

Wang, J. Y., L. S. Chou and B. N. White. 2000. Differences in the external morphology of two sympatric species of bottlenose dolphins (genus Tursiops) in the waters of China. Journal of Mammalogy 81:1157-1165.

Waring, G. T., E. Josephson, C. P. Fairfield-Walsh and K. Maze-Foley, eds. 2009. U.S. Atlantic and Gulf of Mexico Marine Mammal Stock Assessments 2009. U.S. Department of Commerce, NOAA Technical Memorandum NMFS-NE-210. 440 pp.

Yonekura, M., S. Matsui and T. Kasuya. 1980. On the external characters of Globicephala macrorbynchus off Taiji, Pacific coast of Japan. Scientific Reports of the Whales Research Institute, Tokyo 32:67-95.

Received: 5 October 2010

Accepted: 16 February 2011 